\title{
A Comparative Study on Elderly-Friendliness between Traditional Residential Communities and Modern Communities Based on the Analysis of Behaviour-Environment Coupling Degree Take Suzhou as an example
}

Zihan YANG, Southeast University, China

\begin{abstract}
Nowadays, like most ancient cities in China, Suzhou Ancient City is currently facing a serious aging problem. The Suzhou government believes that this issue results in a decline in the proportion of the labour force, which further affects the industrial development and vitality of the ancient city. Therefore, government agencies intend to relieve some of the elderly population through policy measures. However, the modernized ultra-large spatial scale communities pose challenges to the daily travel behaviour of the elderly. This research adopts accessibility, comfortableness, diversity and participation to measure the healthy level of community environment, and uses survival behaviour, family behaviour, spontaneous behaviour and group behaviour to measure the behaviour diversity of the elderly. Both of them constitute a behaviourspatial coupling evaluation index system to quantify the interaction between the behaviour of the elderly and the public space, and then reflect the difference in the suitability of the two types of communities. This study has found that the traditional residential areas in the ancient city have higher coupling and coordination and are more suitable for the elderly to live in, providing a basis for the old people in the ancient city to live in their old lives.
\end{abstract}

\section{Keywords}

Aging; Environmental Behaviour; Coupling and Coordination; Historical and Cultural City; Fitness to the Aged 


\section{Research background and purpose}

The aging of the population has become a serious global problem, and China has already entered an aging society. According to the seventh census data of the National Bureau of Statistics of China in 2020, the population of China aged 60 and over is 26,402 million, accounting for $18.7 \%$ of the total population. Compared with the sixth census in 2010, the proportion of the population aged 60 and over in China increased by 5.44 percentage points (Zhang, 2013). Internationally, the population over 60 years old accounted for $10 \%$ of the total population, or the population over 65 years old accounted for $7 \%$ of the total population as the standard for countries and regions to enter the aging process. China has entered an aging society since 2000 and is currently entering a "moderately aging" society. However, due to natural aging process and the migration of non-elderly populations, the aging of the population in the ancient urban areas of many historical and cultural cities has become more prominent. The proportion of elderly people is much higher than the average level in the whole urban built-up areas, such as Beijing, Shanghai, Xi'an, Hangzhou and Suzhou, etc. Take Suzhou as an example, according to the 7th census population data of Gusu District where the ancient city of Suzhou is located, the population over 60 years old accounted for $33.56 \%$ of the total population in the district, and those over 65 accounted for $18.39 \%$ of the total population in the district, which is much higher than the average level of whole urban built-up area of Suzhou (Yin et al., 2014).

However, the Suzhou local government believes that due to the increasingly prominent problem of aging, the proportion of the labour force in the ancient city is decreasing gradually, which reduces the vitality of the central city. The Suzhou local government hopes that through the transformation of traditional houses in the ancient city and other old residential area, monetary compensation or cross-regional resettlement for the elderly in the ancient city will be appropriately evacuated to relieve the pressure on the elderly population. At the same time, through policy guidance to attract young people to live in the old city, reduce the ratio of old to young in the ancient city, increase the proportion of the working population, and revive the industrial development and economic vitality of the ancient city. However, according to the aging strategy of "healthy aging" (Dixon, 2021) and "positive aging" (Gergen and Gergen, 2001) advocated by WHO, it is proposed that not only the physical health of the elderly, but also the mental health and emotional comfort of the elderly should be paid attention to, in order to accomplish the comprehensive health of the elderly (Moulaert and Garon, 2016). At the same time, it is advocating that the traditional concept of taking the elderly population as a negative social burden should be changed, and it should be treated as a positive social resource, so that the potential of the elderly should be fully realized and utilized (Will and James, 2013). Therefore, this study takes the ancient city of Suzhou as an example, and pays particular attention to whether the passive resettlement of the elderly in the ancient city will affect the physical and mental health of the elderly? The ancient city of Suzhou, which has entered an aging society, how should the interests of the elderly be taken into account when facing the protection and renewal of the ancient city?

This study firstly conducted in-depth interviews and questionnaire surveys to study and summarize the strong willingness of the elderly in the ancient city to live in their old age. Then, based on the related theories of behaviour-environment coupling effects, taking the 15th block of the ancient city of Suzhou as an example, taking the modern resettlement residential area in Xiangcheng District of Suzhou as a comparison, through field investigation and coupling coordination analysis, the community space environmental elements and the behaviour of the elderly are used to conduct the interactive research. From the theoretical perspectives of "healthy aging" and "positive aging", this research analyses the coupling relationship between the temporal and spatial behaviour of the elderly and the living space, and builds an evaluation index system for the coupling of behaviour and living environment of the elderly. Through comparation and judgement the difference in elderly-friendliness between the traditional neighbourhoods in the ancient city and the modern resettlement residential area, so as to provide a basis for the old people in the ancient city to live in their old age. 


\section{Research methodology}

\subsection{Cognition of behaviour-environment relationship}

The elderly suddenly emerged from the previous regular work and life and intensive social relations, and the interactive space of daily life in the neighbourhood became the main container for releasing a lot of their free time and performing various daily activities (Xiong and Lei, 2019). The interactive space of daily life carries two important subsystems: behaviour and environment, which construct a social space structure based on the interaction between body behaviour and environment. The concept of daily life interactive space not only includes physical space, but also pays more attention to the cultural and social attributes of space, that is, the all-round interactive relationship between space and people (Bao and Xiao, 2019). Therefore, the environment studied in this paper includes the hard human settlement environment and the soft human settlement environment $(\mathrm{Wu}, 2001)$. Among them, the hard human settlement environment mainly includes the spatial form and scale, as well as places and facilities, while the soft human settlement environment mainly refers to the social and cultural environment (Chai, 2014). Jan Gale divides behavioural activities into necessary behaviours, spontaneous behaviours and social behaviours (Gehl, 1987). Necessary behaviours for the elderly include survival behaviours and family behaviours, such as grocery shopping, medical treatment, family care, and other necessary daily activities. Spontaneous behaviours may only occur when external environmental conditions are appropriate, such as entertainment, recreational walks, social chats, etc. Social behaviours refer to group activities initiated for the common goal, such as participate in community governance (Zhou and Chai, 2013).

According to the theory of "healthy aging", it aims to achieve the overall health goals of physical and mental health of the elderly, individual and group health of the elderly, and the health of the social and cultural environment (Loo et al., 2017). Therefore, as the subject of behaviour, the elderly have two requirements for the environment in order to achieve their own comprehensive health: the need for spatial material coexistence and the need for social cultural consensus (Zhou and Chai, 2013). When the hard living environment and the necessary behaviours of the elderly present a benign coexistence relationship, and the soft living environment meets the needs of the social cultural consensus of the elderly, it can trigger the spontaneous behaviour of the elderly, and under the chain reaction in the behavioural activities, spontaneous behaviours have contributed to more comprehensive social behaviours. Similarly, diversified social behaviours can also effectively shape physical environmental elements, and further activate social environmental elements such as emotion, history, and humanities (Chai, 2010). When the living space environment of the elderly has a strong social and cultural atmosphere, the interaction between people and the environment continues to increase, which in turn activates the sense of belonging and identification of the elderly in the living place. Studying the relationship between the generation of behaviours of the elderly and the shaping of the environment in communities is of great significance to the realization of the overall health of the elderly individuals and groups, physical and psychological.

\subsection{Cognition of the coupling effect of behaviour and space in the elderly}

The behaviour-environment coupling effect is essentially a kind of interdependent and coordinated relationship between people's behaviour and the environment in a specific interaction space (Ren and Xu, 2017). Associate the behavioural activities of the elderly with the daily life space, and analyse the mechanism between behaviour and environment (Xu et al., 2019). On the one hand, by improving the healthy development of living environment stimulating the multiple daily behaviours of the elderly, and then guiding the elderly to adopt a healthy lifestyle. On the other hand, according to the healthy lifestyle of the elderly, the demand for space health is proposed, and the living space pattern is further optimized, and promote the space become fair, efficient, comfortableness and elderly-friendly (Xu et al., 2017). In 
conclusion, behaviour and environment promote each other and develop in coordination in multiple directions and at multiple levels. With the multiplication effect, a highly compatible man-land coupling system is formed. The healthy development of living space promotes the healthy lifestyle of the elderly, which further promotes and guide the precise development of living spaces (Figure 1). According to the behaviour-environment relationship analysis, it can be judged that the degree of behaviour-environment coupling effect is strong or weak. If the environment and behaviour are a mutually promoted, coordinated and interactive relationship, it can be called a benign coupling; if the coupling between the two is weak and does not promote each other well, it can be called a weak coupling. In addition, if the two show a negative phenomenon of mutual resistance, it is called a non-coupling effect.

Taking the No.15 neighbourhood in the ancient city of Suzhou as an example, the width of the streets and lanes in this neighbourhood is between 2 and 8 meters(Yang, 2019). The narrow lanes limit the number and speed of motor vehicles, which makes it a safer and more comfortable travel environment for the elderly with poor response ability and slow movement. It is conducive to stimulating the spontaneous activities and social behaviours of the elderly to go outside. In such a positive environment, the behaviour of the elderly has a positive coupling relationship with the environment. Another example is Taiyuan Homeland, a resettlement modern community in Xiangcheng District, Suzhou. The resettlement residential area covers an area of about 15 hectares, which is large for the elderly and beyond the comfortable walking range of the elderly. At the same time, because there is no underground parking lot, most of the vehicles are parked on the side of the road, and some internal passageways and public activity spaces between buildings are occupied by vehicles. It has a great impact on the behaviours of residents in the community. The travel and activities of the elderly are restricted by space, people and the space environment lack interaction, and the coupling relationship between behaviour and environment is weak, that is the weak coupling effect.

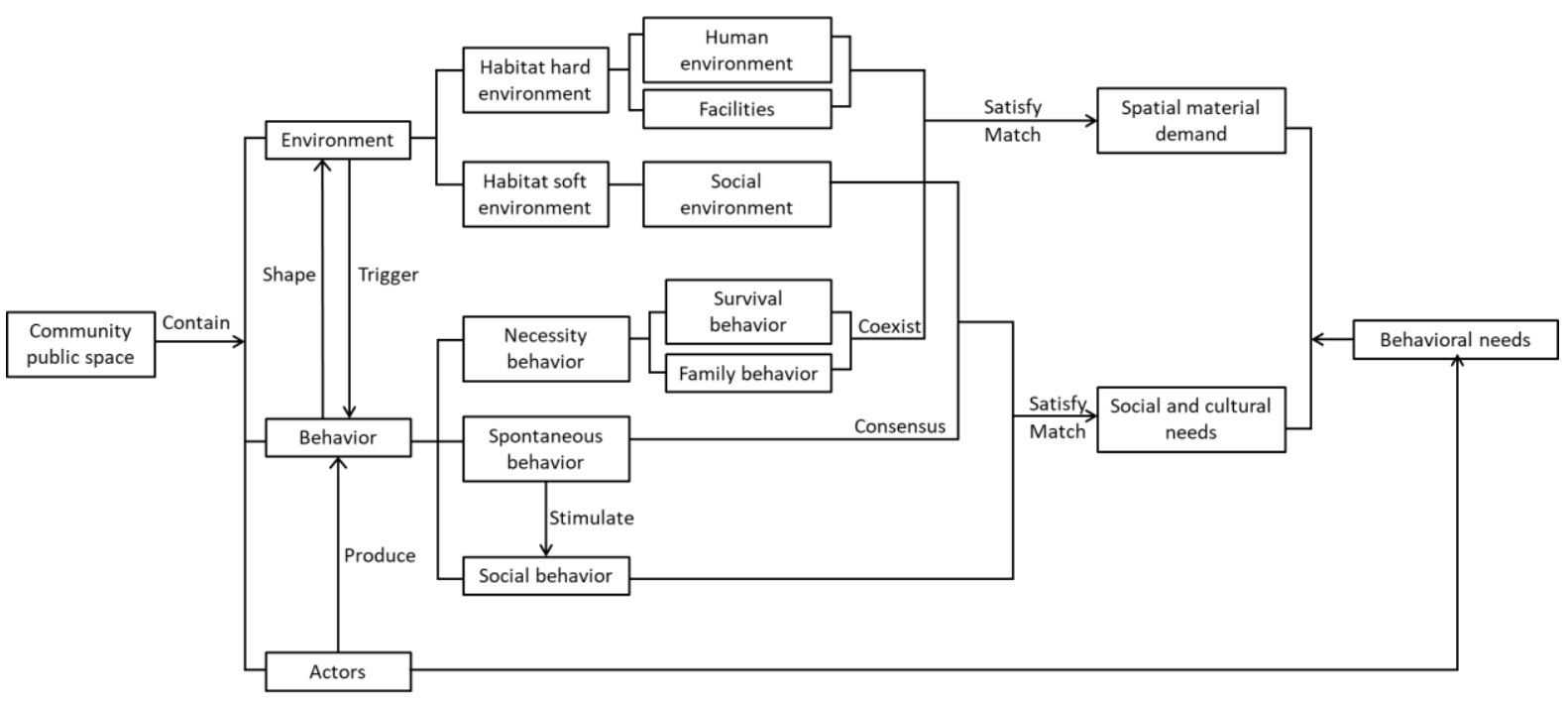

Figure 1 Behavior-environment interaction model. Source: Author.

\subsection{Evaluation method}

Based on the coupling effect of the behaviour environment, the closer the coupling relationship between behaviour and environmental systems, the greater the role of the linkage, and the environment can match the behavioural needs of the elderly more significantly, so the environment is more elderlyfriendly. The comprehensive evaluation analysis method is used to determine the evaluation factors of the behaviour and environmental system and the weight coefficients of each factor, and finally a comprehensive evaluation model of the behaviour and environmental system is constructed. Using the 
survey method that includes observation, questionnaire survey and in-depth interview, combined with GPS technology to collect and process the Behaviour trajectory of the elderly's daily activities (Li and Zhen, 2019). Through summarize the existing behavioural laws of the elderly through the superposition of the trajectory of the elderly, the behaviour system of the elderly includes four types: survival behaviours, family behaviours, spontaneous behaviours and social behaviours. Survival behaviours mainly include daily grocery shopping, medical treatment and other behaviours. Family behaviours mainly include transporting grandchildren, entertaining and dining, and other behaviours. Spontaneous behaviours mainly include walking and hanging out, exercising, playing cards, square-dancing, and social chatting. Social behaviours mainly include mutual assistance behaviours between the elderly (such as providing free hairdressing services), participation in community governance and other behavioural activities. Frequency (weekly The number of times of use per capita) of use of agricultural market, medical facilities, kindergarten, primary and secondary education facilities, commercial facilities, street corner vacancies and other informal spaces, cultural facilities, sports facilities, street furniture (tables and chairs), square, park and the frequency (the number of times of participation per capita per week) of participation in community public affairs are used to measure the diversification of behaviours of the elderly, thereby reflecting the extent to which the community environment stimulates the behaviour of the elderly.

From the aspects of accessibility, comfortableness, diversity, participation, and to construct an evaluation index system for the healthy level of the elderly's daily life space. Accessibility mainly reflects the utilization efficiency of the facility by the elderly, reflects the matching degree between the space life service facilities and the necessary behaviours of the elderly. Based on the current road traffic network, the ArcGIS network analysis method is used to divide the service scope of the medical, elderly care, commercial, cultural, park and other facilities under the walking mode of the elderly with $5 \mathrm{~min}, 10 \mathrm{~min}$, and $15 \mathrm{~min}$ as time intervals, in order to measure the coverage rate of the facilities(Jiang et al., 2014). Comfortableness and diversity mainly reflect the stimulation of the spontaneous behaviour of the elderly by the suitable living environment, adopting the coverage of barrier-free facilities and public space greening rate, as well as the types of medical, elderly care, commercial and open space to the measurements of the comfortableness and diversity. Express. Participation reflects the social participation and collective social cohesion of the elderly, expresses the motivation of the elderly's social behaviour, and uses the density of the active crowd to measure.

Using the survey method including observation, questionnaire survey and in-depth interviews, combined with GPS technology, the behaviour-spatial data of the elderly in the No. 15 neighbourhood in the ancient city of Suzhou and the modern resettlement residential area of Taiyuan Homeland in Xiangcheng District were collected. Due to the inconsistency of attributes and dimensions in the original values of the indicators, it is impossible to compare them horizontally (Li and Zhen, 2019). Therefore, before performing factor analysis, use SPSS 20.0 to standardize the original value of behaviour-spatial indicators. At the same time, SPSS is used to carry out the principal component matrix of the data to further calculate the weight of each evaluation factor (Table 1). Based on the research framework and index system, an evaluation model is constructed to systematically analyse the evaluation indexes of the elderly behaviour $\mathrm{g}(\mathrm{x})$ and environment $\mathrm{f}(\mathrm{x})$. According to the evaluation model, the measurement results of the multiple behaviours of the elderly and the health level of the daily life environment are calculated quantitatively, and draw the behaviour-environment scatter diagram of the elderly. Finally, qualitatively and quantitatively analyse the strength of the coupling relationship between multiple behaviours and the environment, so as to reflect the appropriate aging degree of different kinds of communities. 
Yang, Z.H.

A Comparative Study on Elderly-Friendliness

between Traditional Residential Communities and Modern Communities Based on the Analysis

of Behavior-Environment Coupling Degree

$$
g_{(x)}=\sum_{i=1}^{m} w_{i} x_{i}
$$

$(g(x)$ is the multiple behaviours of the elderly, $x i$ is the quantitative measure of the behaviour of the elderly, and $w i$ is the weight of the evaluation factor, $(i=1,2 \ldots 12))$

$$
f_{(y)}=\sum_{i=1}^{m} w_{i} y_{i}
$$

$(f(x)$ is the healthy level of daily life environment, $y i$ is the quantitative measurement index of the space environment, and $w i$ is the weight of the evaluation factor, $(i=1,2 \ldots 13))$

Table 1 Behavior-Spatial Coupling Index Evaluation System. Source: Author.

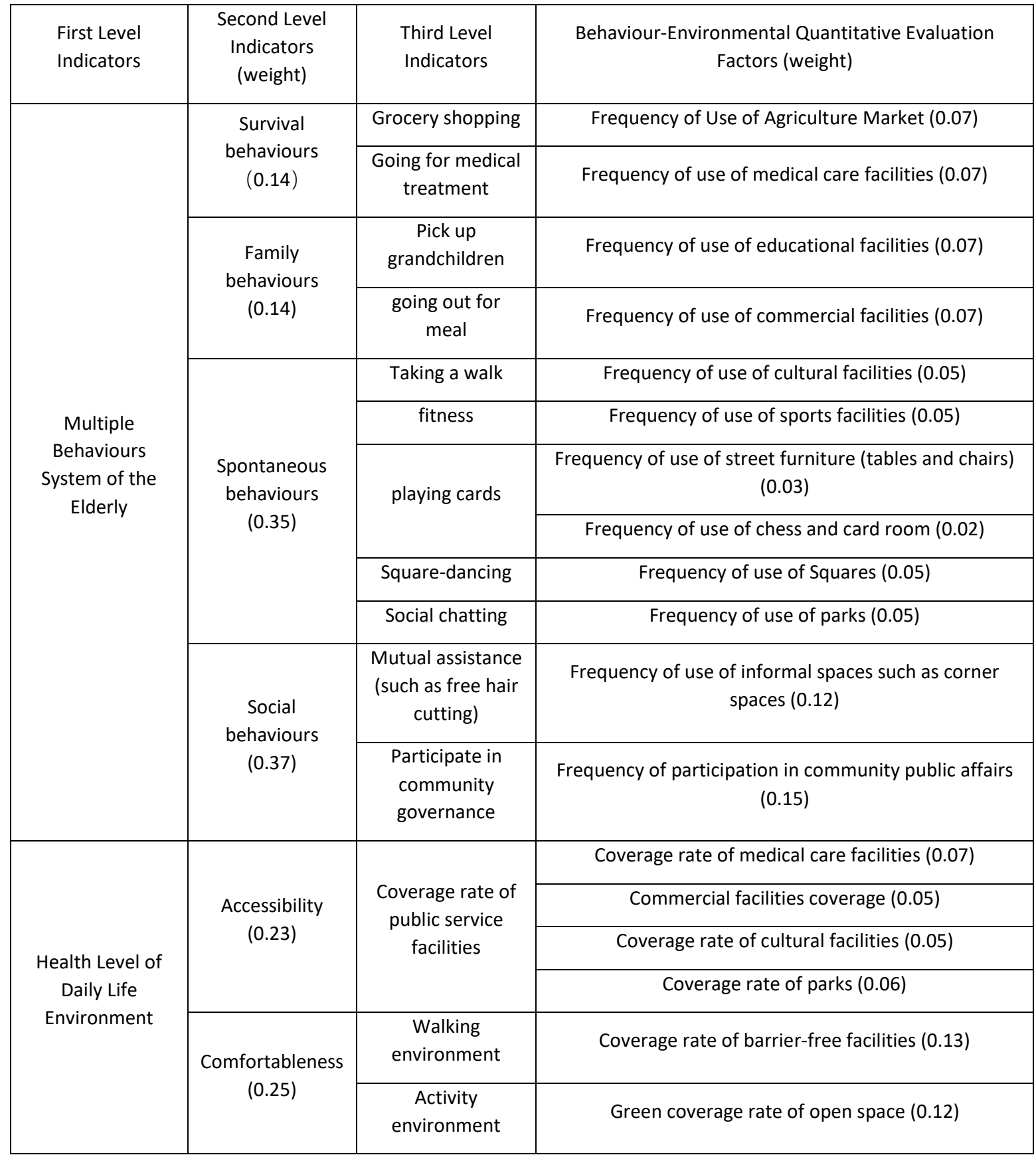




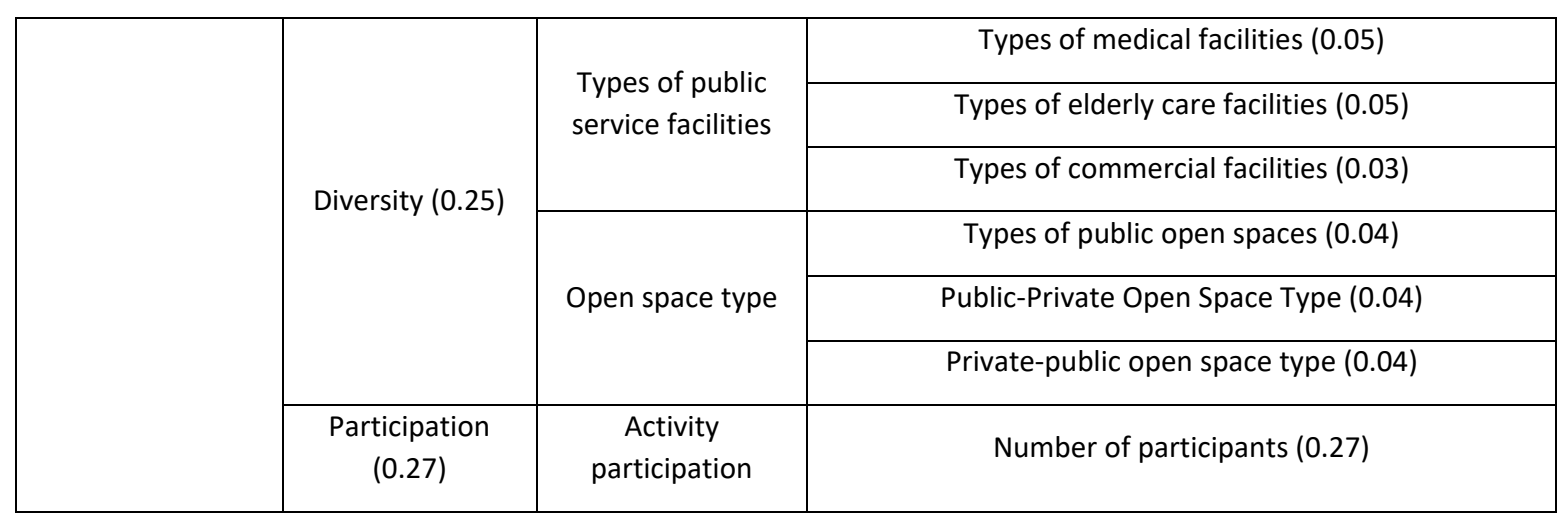

\section{Selection of Case Study Objects}

\subsection{The No.15 Neighbourhood of Suzhou Ancient City}

In 1986, the Suzhou Planning Department and Tongji University jointly cooperated on the protection of the ancient city(Lin and Ruan, 2006). According to the streets and lanes of the ancient city, the direction of the river, and the combination, the city was roughly divided into 54 neighbourhoods. The Case No.15 Neighbourhood is located in the northwest of the ancient city (Figure 2), adjacent to the moat to the west, with a total land area of about 32.9 hectares (Figure 3). There are art gardens and other historical and cultural relics in the neighbourhood. In addition, the land is mainly for residential use, and most of them are traditional dwellings. In the No. 15 neighbourhood of Suzhou Ancient City, the buildings are dominated by 1 to 2 floors. Most of them are built during the Republic of China, and there are also many well-preserved Ming and Qing dwelling. The road network in the neighbourhood is dense, and the scale of the streets and lanes is relatively small, mostly at $2-8 \mathrm{~m}$. There are hospitals, community clinics, community health service centres, elderly apartments, public toilets in the neighbourhood. People aged 70 and above account for a relatively small proportion, and those aged 50 to 69 account for a higher proportion, and most of them can continue to provide labour within their capacity.

\subsection{Taiyuan Homeland, Xiangcheng District, Suzhou}

Taiyuan Homeland is located in Xiangcheng District, Suzhou City (Figure 2), built in 2005. It is a residential area for resettlement people whose original apartment expropriated by the government. It covers an area of approximately 63,000 square meters and has 92 residential buildings (Figure 4). The greening rate of this residential area reaches $20 \%$, and the plot ratio is 1.6 . Taiyuan Homeland is about 1.6 kilometres away from Fuyuan Road Station, which is the nearest subway station, and 100 meters away from the Chengyue Road-Taiyuan Road North Bus Station. Meanwhile, there is a Suzhou Ruisheng Rehabilitation Hospital near the residential area (about 2.2 kilometres away). There are seven kindergartens, two elementary schools, five middle schools. Moreover, there are many supermarkets near the residential area, and the nearest Lianhua convenience store is about 67 meters away. 


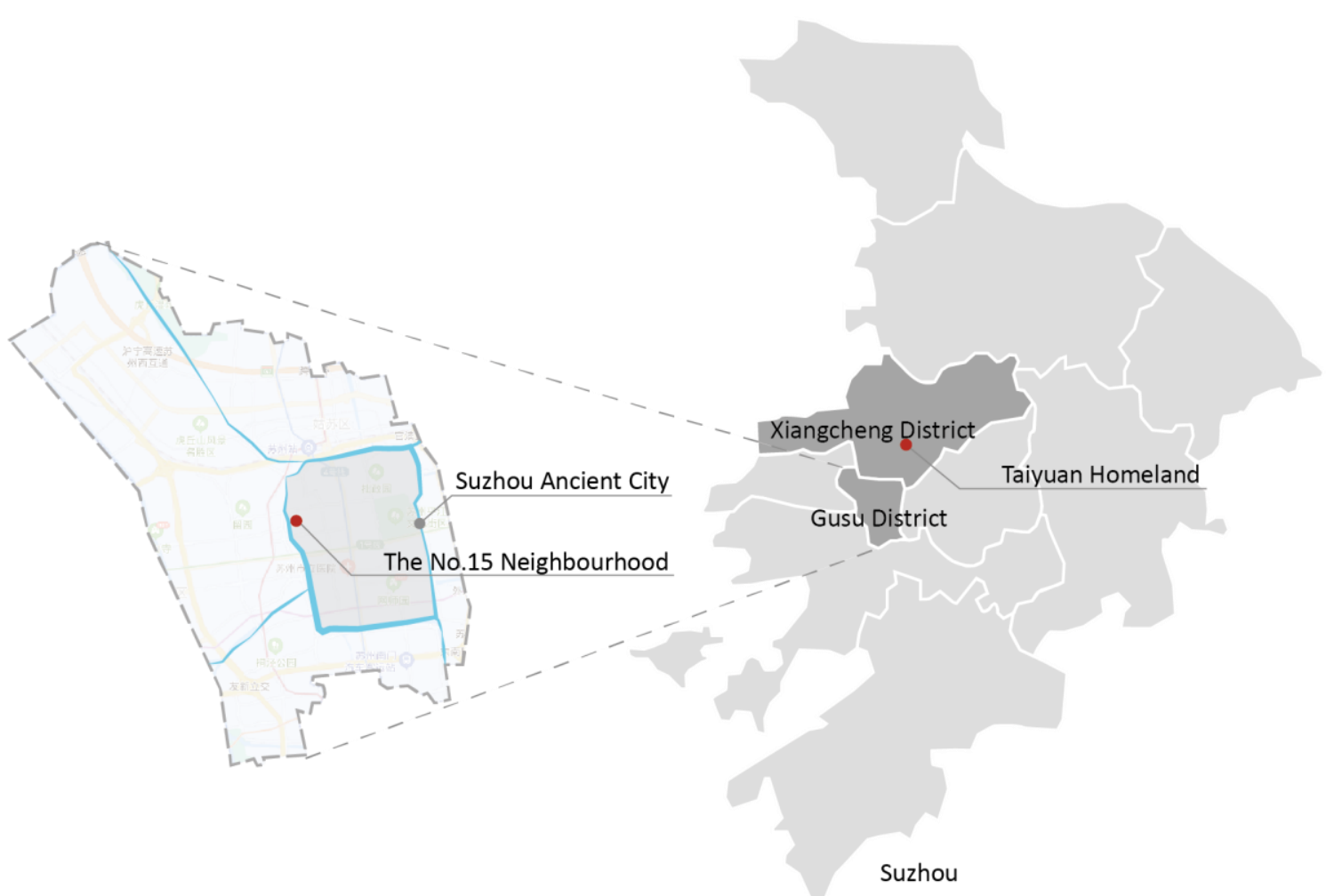

Figure 2 Location of No. 15 Neighborhood and Taiyuan Homeland in Suzhou City. Source: Baidu Map.

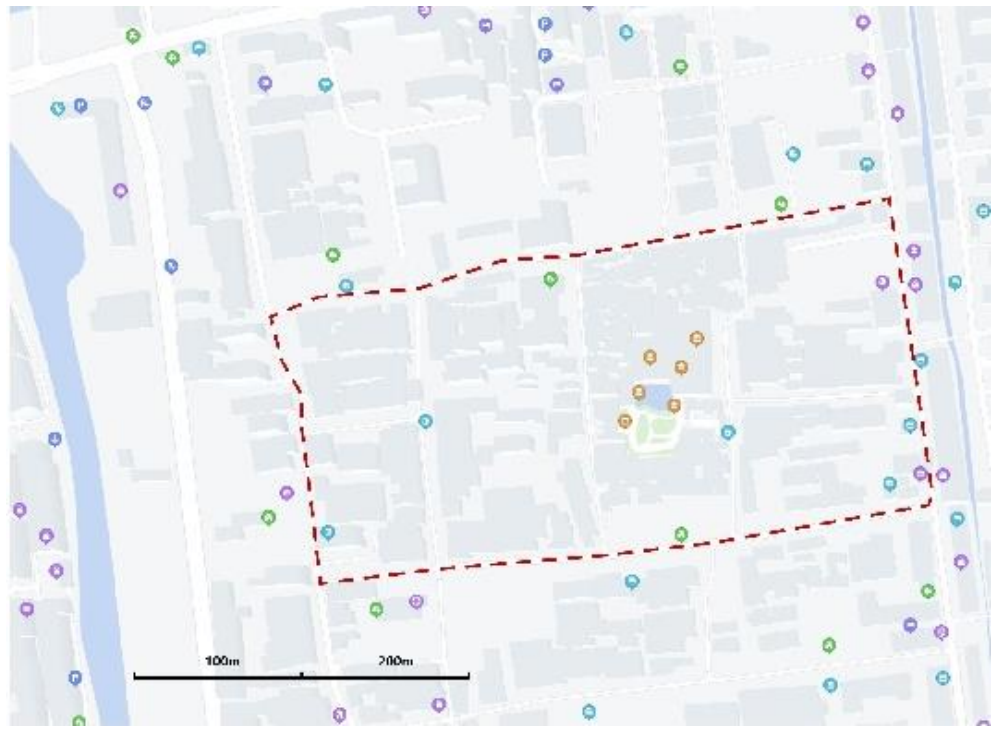

Figure 3 Research Scope of No. 15 Neighborhood. Source: Baidu Map. 


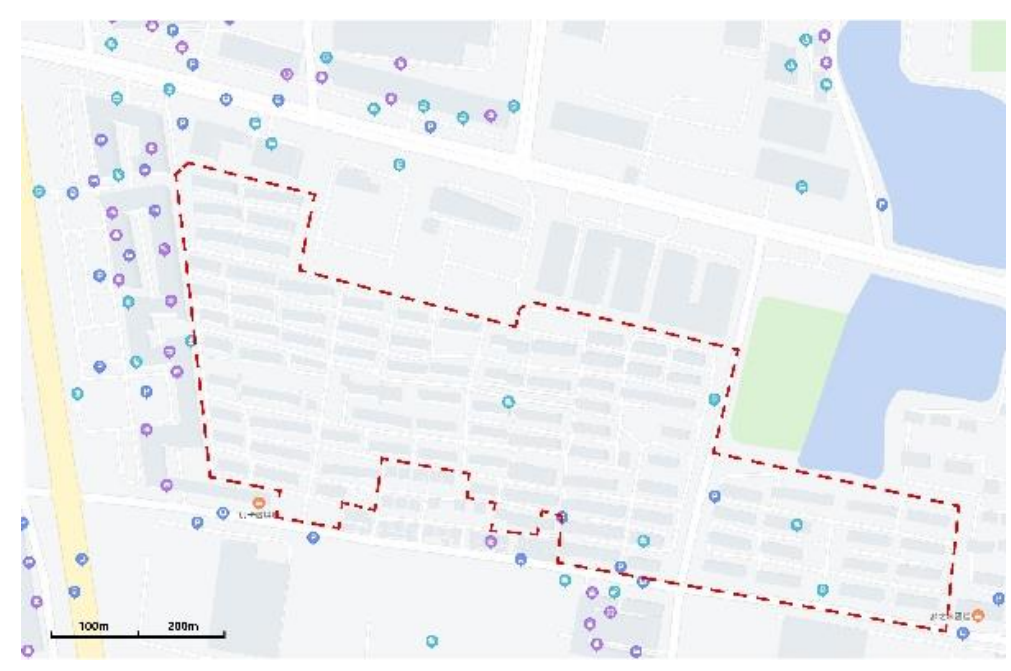

Figure 4 Research Scope of Taiyuan Homeland. Source: Baidu Map.

\section{Research results}

\subsection{Evaluation and analysis of behaviour-environment coupling effects}

According to the behaviour-environment system evaluation results of the No. 15 neighbourhood in Suzhou Ancient City and Taiyuan Homeland in Xiangcheng District (Table 2, Table 3), the behaviourenvironment coupling degree diagram is drawn, and the analysis shows that:

The behaviour-environment coupling relationship of the No.15 neighbourhood a high-level coupling type (Figure 5), Taiyuan Homeland appears low-level coupling (Figure 6). In the No. 15 neighbourhood of Suzhou Ancient City, survival behaviours and family-type behaviours have a good matching degree with the evaluation indicators of the accessibility and comfortableness of the space environment, while the grade of spontaneous behaviours and the diversity of the environment index shows slightly lower than the grade of the spatial environment index. Meanwhile, the index of social behaviour and the participatory behaviour appears that the grade of the spatial environment index are slightly higher than the spatial environment index. In general, the behaviour of and the environmental system have a benign coupling relationship that promotes and complements each other in the No. 15 neighbourhood of Suzhou Ancient City (Figure 5).

In the resettlement area of Taiyuan Homeland in Xiangcheng District, the grades of survival and family behaviours indicators are higher than the grades of al accessibility and comfortableness indicators of environment, while the grades of spontaneous and social behaviours indicators are lower than the grades of diversity and participatory indicators of environment. In summary, the environment system of the Taiyuan Homeland in Xiangcheng District basically meets the spatial needs of the elderly's basic survival behaviours and family behaviours, but lacks the spatial elements that stimulate the elderly's spontaneous behaviours and social behaviours. Therefore, the reshaping effect of the elderly's social behaviours on space is also minimal, and the interaction between behaviour and the environment system is relatively weak and low-coupling (Figure 6). 
Yang, Z.H.

A Comparative Study on Elderly-Friendliness

between Traditional Residential Communities and Modern Communities Based on the Analysis

of Behavior-Environment Coupling Degree

Table 2 Evaluation factor data of behavioral system. Source: Author.

\begin{tabular}{|c|c|c|c|c|c|c|c|c|c|c|c|c|}
\hline & \multicolumn{2}{|c|}{$\begin{array}{c}\text { Survival } \\
\text { behaviours }\end{array}$} & \multicolumn{2}{|c|}{$\begin{array}{c}\text { Family } \\
\text { behaviours }\end{array}$} & \multicolumn{5}{|c|}{ Spontaneous behaviours } & \multicolumn{2}{c|}{$\begin{array}{c}\text { Social } \\
\text { behaviours }\end{array}$} \\
\hline $\begin{array}{c}\text { Evaluation } \\
\text { factors }\end{array}$ & $\mathrm{x} 1$ & $\mathrm{x} 2$ & $\mathrm{x} 3$ & $\mathrm{x} 4$ & $\mathrm{x} 5$ & $\mathrm{x} 6$ & $\mathrm{x} 7$ & $\mathrm{x} 8$ & $\mathrm{x} 9$ & $\mathrm{x} 10$ & $\mathrm{x} 11$ & $\mathrm{x} 12$ \\
\hline $\begin{array}{c}\text { The No.15 } \\
\text { Neighbourhood }\end{array}$ & 8 & 3 & 5 & 2 & 7 & 4 & 11 & 6 & 5 & 9 & 7 & 4 \\
\hline $\begin{array}{c}\text { Taiyuan } \\
\text { Homeland }\end{array}$ & 4 & 2 & 5 & 3 & 1 & 0 & 3 & 2 & 2 & 2 & 1 & 0 \\
\hline
\end{tabular}

Table 3 Evaluation factor data of environmental system. Source: Author.

\begin{tabular}{|c|c|c|c|c|c|c|c|c|c|c|c|c|c|}
\hline & \multicolumn{4}{|c|}{ Accessibility } & \multicolumn{3}{c|}{ Comfortableness } & \multicolumn{3}{c|}{ Diversity } & Participation \\
\hline $\begin{array}{c}\text { Evaluation } \\
\text { factors }\end{array}$ & $y 1$ & $y 2$ & $y 3$ & $y 4$ & $y 5$ & $y 6$ & $y 7$ & $y 8$ & $y 9$ & $y 10$ & $y 11$ & $y 12$ & $y 13$ \\
\hline $\begin{array}{c}\text { The No.15 } \\
\text { Neighbourhood }\end{array}$ & $100 \%$ & $75 \%$ & $100 \%$ & $96 \%$ & $37 \%$ & $47 \%$ & 3 & 4 & 4 & 2 & 3 & 3 & 23 \\
\hline $\begin{array}{c}\text { Taiyuan } \\
\text { Homeland }\end{array}$ & $30 \%$ & $88 \%$ & $21 \%$ & $35 \%$ & $11 \%$ & $23 \%$ & 1 & 1 & 3 & 2 & 1 & 0 & 5 \\
\hline
\end{tabular}

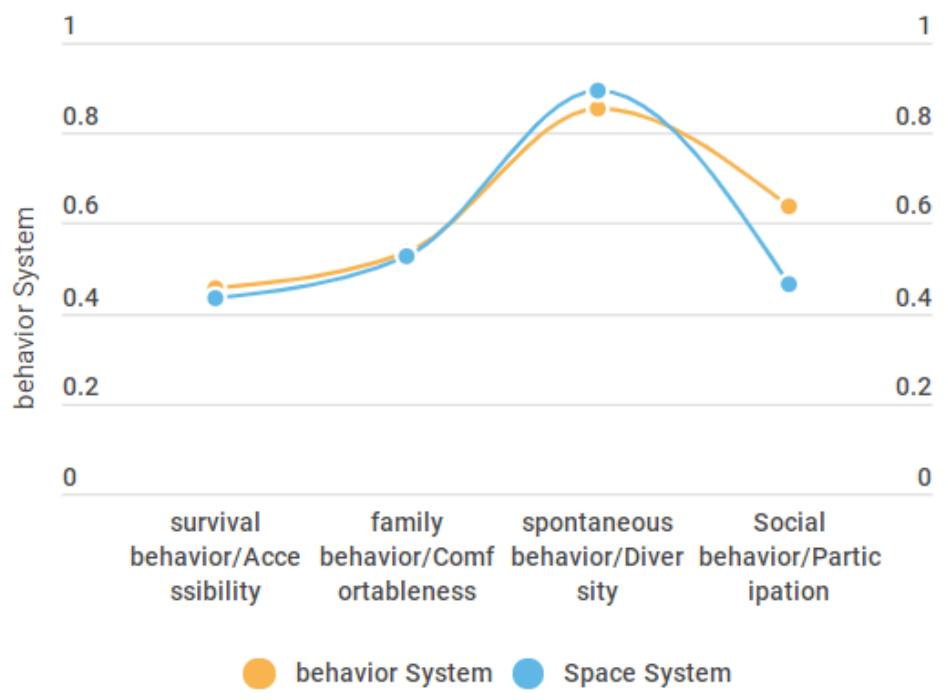

Figure 5 Behaviour-environment scatter diagram of No.15 Neighbourhood. Source: Author. 


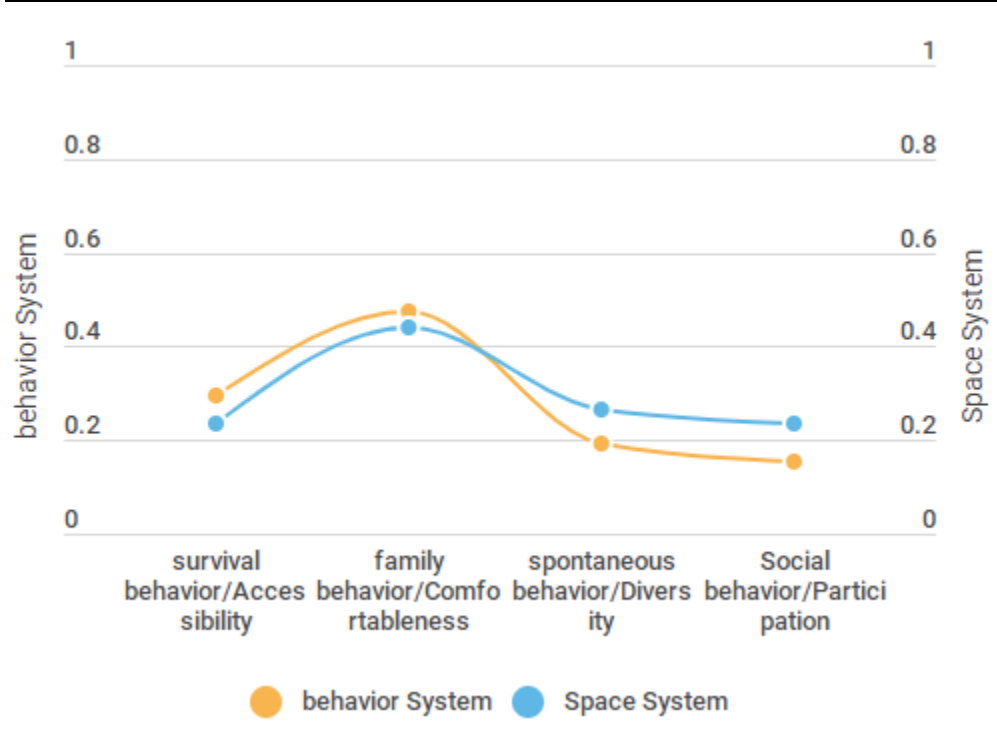

Figure 6 Behaviour-environment scatter diagram of Taiyuang Homeland. Source: Author.

\subsection{Cause analysis of coupling level}

After a comparative analysis of the behaviour-environment coupling between the No.15 neighbourhood of Suzhou Ancient City and the modern resettlement residential area of Taiyuan Homeland in Xiangcheng District, combined with the selected evaluation indicators, the cause analysis of the high-level coupling type presented in the No.15 neighbourhood is carried out:

The space scale and street environment are elderly-friendly. Firstly, as the No. 15 neighbourhood of the ancient city of Suzhou in this survey, most of its ancient residential buildings are 1-2 floors. With the aging of the elderly, the decline in health status, and the aging of musculoskeletal, fewer floors of buildings can reduce the daily troubles caused by going up and down to the elderly and increase the safety of living. Secondly, the width of the streets in the neighbourhood is around 2-8 meters, the narrow lanes limit the number and speed of motor vehicles, thus forming a safer travel environment for the elderly with poor response ability and slow mobility. The age-appropriate space scale and street environment reduce the elderly's dependence on barrier-free facilities, increase the elderly's sense of safety when traveling, and reduce the psychological burden of distance and time when the elderly travel, thus inspiring the occurrence of the elderly's spontaneous behaviour and social behaviour.

Completed public services and diversified forms of open spaces. In the No.15 neighbourhood, within a walking distance of 10 minutes, there are 2 bus stops, 1 community clinic, 1 community health service centre, 1 kindergarten, and 5 public toilets. Within a 15-minute walking distance, there are 2 community service centres, 1 apartment for the elderly, 2 general hospitals, 1 agriculture market and 1 Suzhou Garden(Yang, 2009). In addition, there are more convenient shops and mobile stalls scattered in the neighbourhood, as well as a variety of commercial formats, such as noodle restaurants, vegetable shops, butcher shops, tailor shops, breakfast shops, etc., and most of the goods and services sold are at low prices, which are in line with the consumption needs of the elderly. At the same time, due to the comprehensive protection official development strategy that the ancient city of Suzhou has always adhered to, the organic spatial form of the ancient city has been completely preserved. Comparing with the rigid and homogenous spatial arrangement in modern residential planning, the traditional dwellings in ancient are arranged and organized in an organic manner to form multiple open space forms, such as public open space, public-private open space, private-public open space. Varied forms of open space increase the interest of the space, and also provides opportunities for the elderly to independently organize mutual assistance activities or carry out informal space remodelling. Therefore, the completed 
public service facilities and diversified forms of open spaces in the ancient city can well match the needs of environmental factors for the survival behaviours, family behaviours, and spontaneous behaviours of the elderly.

Familiar neighbourhood relations and lifestyles. The elderly suddenly retire from the regular working-life and dense social relations, facing a lot of free time to release, they are prone to loneliness and loss. If the elderly were evacuated from the ancient city and move into resettlement areas under the arrangement of government, they would lose their original social connections. In a new and unfamiliar community, the sense of loss of the elderly hinders and restricts their spontaneous and social behaviours. However, in such a collective living environment in the No.15 Neighbourhood of the ancient city, familiar neighbourhood relationships and lifestyles provide psychological support for the elderly, enabling them to experience a sense of belonging and identity.

\section{Conclusions and future research plans}

Under the guidance of theories of environmental behaviour and coupling relations, this paper constructs a behaviour-environment relationship model, and builds an evaluation system for behaviourenvironment coupling effects. Taking the No. 15 neighbourhood in the ancient city of Suzhou and the Taiyuan Homeland modern resettlement residential area in Xiangcheng District as an example, a comparative analysis is conducted. Through quantitative analysis, the behaviour-environment coupling relationship and the degree of coupling are studied, and the No. 15 neighbourhood is obtained as behaviour-environment high-level coupling type, while Taiyuan Homeland is low-level coupling type. And combined with the evaluation indicators to analyse the reasons for the differentiation of the coupling level of the behaviour-environment system, which are the elderly-friendly spatial scale and street environment, completed living services and multiple open spaces, and familiar neighbourhood relationships and lifestyles. Compared with the newly developed modern resettlement residential, the behaviour and environment of traditional old dwellings promote each other more significant and present a benign interaction, so the ancient city are more elderly-friendly, and has more possibility to realize the overall health of the elderly. Therefore, this research quantitatively and qualitatively proves from the perspective of Environmental Behaviour that the old residential areas in the ancient city of Suzhou are more suitable for the elderly than the newly developed modern residential areas which are used to resettle the elderly evacuated from the ancient city. This research provides a basis for the old people in the ancient city to live in their old lives. In future investigations and studies, the number of survey samples of traditional dwellings and newly developed residential area in the ancient city should be increased, so that the research data is richer and more complete, and the research conclusions are more scientific and convincing.

\section{References}

Bao, Q. \& Xiao, M. (2019), "Research on Renewal of Public Space in Zhongshan Road Area of Xiamen from the Perspective of Daily Life", Chinese \& Overseas Architecture.

Chai, Y. W. (2010), Activity space for the elderly in Chinese cities, Science Press.

Chai, Y. W. (2014), Space Behaviour and Behaviour Space, Southeast University Press.

Dixon, A. (2021), "The United Nations Decade of Healthy Ageing requires concerted global action", Nature Aging, Vol. 1 No. 1, pp. 2-2.

Gehl, J. (1987), "Life Between Buildings: Using Public Space", Island Press. 
Gergen, M. M. \& Gergen, K. J. (2001), "Positive aging: New images for a new age", Ageing International, Vol. 27 No. 1, pp. 3-23.

Jiang, H. Y., Zhu, X. M., Wu, L. L. \& Zhang, J. R. (2014), "Fair assessment of city public facilities: The measure comparison of physical accessibility and spatial and temporal accessibility", International Urban, Vol. 29 No. 005, pp. 70-75.

Li, Z. Z. \& Zhen, F. (2019), "Evaluation of Urban Life Space Quality Based on Multi-source Data: A case Study of Nanjing", Human Geography, Vol. 34 No. 6, pp. 9.

Lin, L. \& Ruan, Y. S. (2006), "Conservation Planning and Practice for Pingjiang Historic District of Suzhou City", Urban Planning Forum, No. 03, pp. 45-51.

Loo, B. P. Y., Lam, W. W. Y., Mahendran, R. \& Katagiri, K. (2017), "How Is the Neighbourhood Environment Related to the Health of Seniors Living in Hong Kong, Singapore, and Tokyo? Some Insights for Promoting Aging in Place", Annals of the American Association of Geographers, Vol. 107 No. 4, pp.

Moulaert, T. \& Garon, S. (2016), "Age-Friendly Cities and Communities in International Comparison", Springer International Publishing, Vol. 10.1007/978-3-319-24031-2.

Ren, K. \& Xu, L. Q. (2017), "Environmental-Behaviour Studies of Sustainable Construction of the Third Place: Based on Outdoor Environment-Behaviour Cross-Feed Symbiotic Analysis and Verification of Selective Activities", Urban Design, Vol. 02 No. No.010, pp. 77-82.

Will, H. \& James, P. (2013), "The Active Third Age and the Future of the City.", Architectural Review.

Wu, L. Y. (2001), Introduction to Sciences of Human Settlements, Beijing, China Architecture and Building Press.

Xiong, Y. \& Lei, H. X. (2019), "Research on the Renewal Strategy of Community Interactive Space under the Coupling Effect of Behaviour-Environment--Taking the Community of Xi'an Railway Administration as an Example", 2019 China Urban Planning Annual Conference, pp.

Xu, Y. S., Zhou, D. \& Liu, K. J. (2019), "Research on the Visualization of Temporal and Spatial Behaviour of the Elderly and the Healthy and Liveable Environment of Community", Architectural Journal, Vol. No.20 No. S1, pp. 96-101.

Xu, Y. S., Zhou, D. \& Liu, N. (2017), "The Characteristics of Hong Kong's Elderly Service Facilities The Structural Characteristics and Planning Enlightenments of Hong Kong Elderly Service Facility System", Urban Planning International, Vol. 032 No. 006, pp. 77-83.

Yang, J. Q. (2009), "The protection of historical and cultural cities based on the urban development mechanism", Urban Development Studies, Vol. 16 No. 011, pp. 139-142.

Yang, Z. H. (2019), "Study on the Old-age Care Model of the Elderly in the Context of the Protection and Development of Suzhou Ancient City", Urban Development Studies, Vol. 026 No. 012, pp. 33-38.

Yin, J. W., Niu, W. D. \& Xu, Y. H. (2014), "Optimizing the population structure and restoring the vitality of the ancient city-a study on the guidance of population development in the ancient city of Suzhou ", City Planning Review, Vol. 38 No. 005, pp. 50-53.

Zhang, Y. (2013), "Family housing, health and care arrangements for the elderly in China: data analysis of the sixth census", Jiangsu Social Sciences, Vol. 000 No. 001, pp. 57-65.

Zhou, J. \& Chai, Y. W. (2013), "Research progress on spatial behaviours of the elderly in China", Progress in Geography, Vol. 032 No. 005, pp. 722-732. 